\title{
İnovasyon ve Kârlılık Arasındaki İlişki: Otomotiv Sektörü Üzerine Bir Araştırma
}

\author{
Mehmet SANDAL \\ Manisa Celal Bayar Üniversitesi \\ mehmet.sandal@cbu.edu.tr \\ ORCID ID: 0000-0001-7396-0801 \\ Anıl GACAR \\ Manisa Celal Bayar Üniversitesi \\ anil.gacar@cbu.edu.tr \\ ORCID ID: 0000-0002-4571-3886
}

\begin{tabular}{lrr} 
Araştırma Makalesi & DOI: $10.31592 /$ aeusbed.908791 \\
\hline Geliş Tarihi: 02.04 .2021 & Revize Tarihi: 06.07.2021 & Kabul Tarihi: 17.07 .2021
\end{tabular}

\section{Atıf Bilgisi}

Sandal, M. ve Gacar, A. (2021). İnovasyon ve kârlilik arasındaki ilişki: Otomotiv sektörü üzerine bir araştırma. Ahi Evran Üniversitesi Sosyal Bilimler Enstitüsü Dergisi, 7(2), 556-571.

\section{ÖZ}

Dijitalleşme ile ișletmelerin varlığını sürdürebilmesi için doğru hedefler koyması ve performanslarını artırması gerekmektedir. İşletmelerin rekabet üstünlüğü sağlamak ve kârlılıklarını artırmak için en çok ihtiyaç duyulan faktörlerin bașında ise inovatif (yenilikçi) düşünce ile araștırma ve geliștirme faaliyetleri yer almaktadır. Bu çalışmada, otomotiv imalat sektöründe faaliyet gösteren işletmelerin inovasyon ve kârlılıkları arasındaki ilişkinin araştırılması amaçlanmaktadır. Bu amaçla Borsa İstanbul'da imalat sektörü içerisinde yer alan ve otomotiv alanında faaliyet gösteren işletmeler ele alınmıştır. Çalışmada işletme kârlılığını temsil eden iki farklı model oluşturulmuş ve 2016Q1-2020Q4 çeyrek dönemleri için panel veri analizi uygulanmıştır. Bununla birlikte, araştırma amacına uygun ekonometrik model belirlenerek model parametrelerinin tahmin edilmesi için dirençli tahmin yöntemleri kullanılmıştır. Çalışma sonucunda, araştırma ve geliştirme (Ar-Ge) harcamalarının aktif kârlılık oranı (return on assets- ROA) ve özsermaye kârlılık oranı (return on equity- ROE) üzerinde anlamlı ve pozitif bir etkisi olduğu tespit edilerek Ar-Ge harcaması yapan işletmelerin kârlılıklarının arttığı sonucuna ulaşılmıştır. Ayrıca kontrol değişkeni olarak modele dahil edilen kaldıraç oranının ise negatif bir etkisi olduğu gözlemlenmiştir.

Anahtar Kelimeler: İnovasyon, kârlılık, ar-ge harcamaları, panel veri analizi.

\section{The Relationship Between Innovation and Profitability: A Research on Automotive Sector}

\begin{abstract}
Businesses need to set correct targets and increase their performance in order to survive with digitalization. Innovative thinking and research and development activities are at the beginning of the factors that are most needed to ensure competitive superiority and increase business' profitability. This study aims to investigate the relationship between innovation, profitability of enterprises operating in the automotive manufacturing sector. For this purpose, enterprises in the manufacturing sector in Borsa Istanbul and operating in the automotive field were discussed. In the study, two different models representing the business profitability were created and panel data analysis was applied for the 2016Q1-2020Q4 quarter periods. However, by determining the econometric model suitable for the research purpose, resistant estimation methods were used to estimate the model parameters. As a result, it was found that Research and Development (R\&D) expenditures had a significant and positive impact on the return on assets (ROA) and return on equity (ROE) and it was concluded that the profitability of enterprises spending on $R \& D$ increased. In addition, it was observed that leverage ratio included in the model as a control variable has a negative effect.
\end{abstract}

Keywords: Innovation, profitability, R\&D expenditure, panel data analysis.

\section{Giriş}

Kâr elde etmek amaciyla üretim faktörlerini kullanan kişiler, girişimci olarak tanımlanabilir. Girişimciler, serbest mülkiyete dayalı ülkelerde (Amerika Birleşik Devletleri, İngiltere, Fransa, Almanya vb.) ekonomik kalkınmanın belirleyicileri arasında değerlendirilmekte olup bu ülkelerde girişimciler teşvik edilerek yeni işletmeler kurulması amaçlanmaktadır. Bu bağlamda, girişimciliğin ülkelerin gelişiminde önemli bir rol oynadığı kabul edilebilir. 
Son dönemlerde, birçok sektörde işletme sayısının artması, sürdürülebilirlik olgusunu öne çıkarmaktadır. Rakiplerinden daha çok gelir elde etmek ve müşteri kazanmak isteyen işletmeler, ürün ya da hizmetlerinde yeniliği (inovasyon) öne çıkararak farklılaşmak ve bunu bir işletmecilik felsefesi haline getirmek durumundadır. Shumpeter (1934), yenilikçiliğin işletmelerde beş farklı şekilde ortaya çıktığııı belirtmektedir. Buna göre yenilikçilik türleri;

- Yeni bir ürün ortaya konulmas1,

- Ürünlerin hammaddelerinin farklı kaynaklardan edinilmesi,

- Üretim tekniğinde farklılaşma,

- Yeni pazarlarda faaliyet gösterme ve

- Piyasa farklılaşması şeklinde belirtilebilir.

Yenilikçiliği benimseyen işletmelerin, rakipleri karşısındaki performansının daha iyi olacağı ifade edilebilir. Damanpour (1991), Han, Kim ve Srivastava (1998), Cho ve Pucik (2005), Orfila-Sintes ve Mattsson (2009), Öncü, Bayat, Kethüda, Zengin (2015) ile Şişmanoğlu ve Akçalı (2016)'nın çalışmaları, yenilikçiliğin işletme performansını arttırdığına yönelik literatürdeki çalışmalar arasında yer almaktadır. Şişmanoğlu ve Akçalı (2016) ve Çiçek ve Onat (2012) yaptıkları çalışmalarda yenilikçiliğin göstergesi olarak Ar-Ge harcamalarını belirtmektedirler. Zahra ve Das (1993), 149 imalat işletmesi üzerine yaptıkları çalışmada, işletmelerde yenilikçilik stratejilerinin finansal performans üzerinde önemli etkileri olduğu sonucuna ulaşmışlardır. Geroski (1995), yenilikçilik ile pay senedi getirileri, işletme büyüklüğü ve muhasebe kârlılığı arasında pozitif ancak güçlü olmayan bir ilişki olduğunu tespit etmiştir. Ağca ve Karademir (2008), imalat sektörü üzerine gerçekleştirdikleri çalışmalarında, yenilikçilik ile finansal performans arasındaki ilişkiyi belirlemeye çalışmıştır. Çalışma sonucunda, işletmelerde yenilikçilik düzeyi arttıkça kârlılık ve verimliliğin de arttığı sonucu elde edilmiştir. OrfilaSintes ve Mattson (2009), Balearic Adaları'nda 331 otel işletmesi üzerine yaptıkları anket çalışmasında, yenilikçilik düzeyinin işletmelerin finansal performansları üzerinde pozitif bir etkisi olduğu sonucunu elde etmişlerdir. Çiçek ve Onat (2012), geçmiş dönemdeki adıyla İstanbul Menkul Kıymetler Borsası (IMKB)'ndaki bilişi̇m sektöründe faaliyet gösteren 9 işletmenin araştırma ve geliştirmeye dayalı yenilikçilik faaliyetleri ile finansal performansları arasındaki ilişkiyi veri zarflama analizi ile belirlemeye çalışmışlardır. Çalışma sonucunda, analize tabi tutulan 9 işletmeden 5'inin etkin performansa sahip olduğu ortaya konmuştur.

Apergis ve Sorros (2014), 2000-2012 yılları arasında Amerika Birleşik Devletleri'nde 183 yenilenebilir enerji firması üzerine bir çalışma gerçekleştirmiş̧lerdir. Çalışmada, aktif kârlılık ve özkaynak kârlılık oranı bağımlı değişken olarak kullanılırken; Ar-Ge harcamaları ve nakit akışları bağımsız değişken olarak kullanılmıştır. Analiz sonucunda, kârlılık ve Ar-Ge harcamalarının aynı yönde olduğu belirlenmiştir. Şişmanoğlu ve Akçalı (2016), araştırma ve geliştirme harcamaları (yenilikçilik) ile net satışlar (finansal performans) arasındaki ilişkiyi bilişim sektöründe faaliyet gösteren 7 işletme üzerinde incelemişlerdir. Panel veri analizinin kullanıldığı ve 2005-2014 döneminin analize tabi tutulduğu çalışmada, iki işletme üzerinde araştırma ve geliştirme harcamalarının net satışlar üzerinde olumlu bir etkiye sahip olduğu ortaya konmuştur. Dağlı ve Ergün (2017), yaptıkları çalışmada 20102013 döneminde Borsa İstanbul'a kayıtlı ve Ar-Ge harcaması yapan 68 işletmenin firma kârlılı̆̆ 1 ve ArGe harcamaları arasındaki ilişkiyi belirlemeye çalışmışlardır. Çalışmada, firma kârlılı̆̆ 1 olarak aktif kârlılığı oranı kullanılmıştır. Çalışma sonucunda firma kârlılı̆̆ 1 ve kaldıraç oranı arasında istatistiksel olarak anlamlı fakat negatif; Ar-Ge harcamaları ve kârlılık arasında da anlamlı ve pozitif ilişki belirlenmiştir. Gürkan N. ve Gürkan S. (2017), işletmelerin yenilikçilik düzeyi ile finansal performansları arasındaki ilişkiyi panel veri analizi ile ölçmek amacıyla bir çalışma gerçekleştirmişlerdir. Çalışmada, Borsa İstanbul Kurumsal Yönetim Endeksinde 2012-2016 dönemleri arasında bulunan 20 işletmenin verileri kullanılmıştır. Çalışma sonucunda, işletmelerin yenilikçilik düzeyi ve finansal performansları arasında pozitif ve anlamlı bir ilişki olduğu sonucu elde edilmiştir.

Aytekin ve Güler Özçalık (2018), işletmelerin yenilik yapma düzeyini Ar-Ge harcamaları ile ilişkilendirmişlerdir. Çalışmada, 2011Q1-2018Q1 dönemlerinde Borsa İstanbul Teknoloji ve Bilişim Endekslerinde işlem gören 7 işletmenin Ar-Ge ve finansal performans verileri değerlendirilmiştir. Net satışların bağımlı değişken olarak kabul edildiği çalışmada yapılan panel veri analizi sonuçlarına göre 
Ar-Ge harcamaları arttıkça işletmelerin net satış gelirlerinin arttığı sonucuna ulaşılmıştır. Saliba de Oliviera, Cruz Basso, Kimura, Sobreiro (2018), Brezilya' da yer alan 5025 işletme üzerinde yenilikçilik ve finansal performans ilişkisini ortaya koymayı amaçlayan bir faktör analizi gerçekleştirmişlerdir. Çalışma sonucunda, işletmelerin yenilikçilik konusundaki çabalarının yeni ürünlere yol açtı̆̆ belirtilse de yenilikçiliğin riskli ve maliyetli yapısı nedeniyle finansal performansın kısa vadede olumlu yönde etkilenmeyeceği belirtilmektedir. Yıldırım ve Sakarya (2018), Borsa İstanbul'da 2009-2016 dönemlerinde bilişim sektöründeki 16 işletmenin Ar-Ge harcamaları ile aktif ve özkaynak kârlılıkları arasında ne tür bir ilişkinin olduğunu panel veri yöntemiyle ele almışlardır. Çalışma bulgularına göre Ar-Ge harcamaları ile aktif özkaynak kârlılıkları arasında uzun dönemli bir ilişkinin bulunduğu belirlenmiştir. Nedensellik analizinden sonra yapılan regresyon analizi sonucunda ise Ar-Ge harcamalarının aktif ve özkaynak üzerinde olumlu etkisinin varlı̆̆ 1 belirlenmiştir.

$\mathrm{Bu}$ çalışmada da yenilikçiliğin finansal performansa etkisinin araştırılması amaçlanmıştır. $\mathrm{Bu}$ kapsamda, Borsa İstanbul'da imalat sektörü içerisinde yer alan ve otomotiv alanında faaliyet gösteren işletmelerin 2016-2020 dönemlerindeki çeyreklik olmak üzere toplam 20 dönem verileri analize dahil edilerek yenilikçiliğin finansal performans üzerindeki etkisi inceleme konusu yapılmıştır. Çalışmanın birinci bölümünde yenilikçilik ve finansal performans konularında kavramsal bilgilere yer verilmiş olup ardından bu iki kavram arasındaki ilişkiyi konu alan çalışmalar özetlenmeye çalışılmıştır. İkinci bölümde, Borsa İstanbul'da yer alan ve 2016-2020 döneminde verilerine eksiksiz ulaşllabilen otomotiv alanında faaliyet gösteren işletmeler çalışmanın örneklemi kabul edilmiş ve analizde yararlanılan model ve kullanılan yöntem hakkında bilgilere yer verilerek çalışmanın bulguları belirtilmiştir. Sonuç bölümünde ise yapılan analiz sonucunda yenilikçilik ve finansal başarı ilişkinin varlığı belirlenerek gelecekte yapılabilecek çalışmalar hakkında önerilere yer verilmiştir.

\section{Finansal Performans Kavramı}

Performans, işletme hedefleri doğrultusunda yapılmış faaliyetler sonucunda elde edilen kalitatif ya da kantitatif ölçütler olarak kabul edilebilir. Performans genel anlamda, belli bir zaman sonunda ortaya çıkan sonuçtur (Bolat, 2000, s.105). İşletmeler açısından performans, işletmelerin amaçlarının gerçekleştirilmesi sürecinde gösterilen tüm nicel ve nitel değerlendirmelerin yapılması şeklinde belirtilebilir (Akal, 2005, s.17). Nicel değerlendirmeler satış gelirleri, kârlılık, varlık (aktif) büyüklüğü, özsermaye tutarı vb. sayısal değerler; nitel değerlendirmeler ise yönetim şekli, müşteri memnuniyeti vb. unsurlar olabilir.

Finansal performans aracılığıyla işletmelerin finansman yapıları, geçmiş yatırımları ve bu yatırımların verimlilik durumu; bununla birlikte işletmenin zarara uğrama olasıllı̆ı ortaya konabilmektedir. Öte yandan finansal performans ile geçmiş dönemlerde oluşan verilerin doğru olarak ele alınması ve daha sonraki dönemlerde yapılması planlanan yatırımların finansman kaynakları konusunda önemli bilgiler elde edilebilmektedir (Uygurtürk ve Korkmaz, 2012, s.96). Buna ek olarak, işletmelerin yatırım verimliliği ya da kredibilitesi konusunda karar alıcı durumunda bulunan ortaklar ve kredi veren kuruluşlar, finansal performans ölçümü yardımıyla karar almaktadırlar (Aytekin ve Sakarya, 2013, s.31).

\section{İnovasyon (Yenilikçilik) Kavramı}

Yenilikçi olmak, işletmeleri birbirinden ayıran önemli ve ayırt edici bir unsur olarak değerlendirilebilir. Ürün ya da hizmetlerinde yenilik yapan işletmeler, faaliyetlerini rakiplerine göre daha farklı ve öncü hale getirmektedir. Rekabette öne geçmek isteyen işletmelerin ürün ya da hizmetlerinde yenilik yapması kaçınılmaz görünmektedir. Çünkü, teknolojinin yoğun kullanımı sonucunda çok fazla işletme kurulabilmekte ve bu durum da müşterilerin seçeneklerini genişletebilmektedir. Çok fazla seçeneği olan müşteri de yenilikçi işletmeleri daha çok tercih edebilmektedir. Yenilikçilik kavramı yalnızca ürün ya da hizmetleri ile ilgili olmayıp; sistem, süreç, pazarlama ve bireylerin sürekli yenilenmesi üzerine kuruludur (Kavak, 2009, s.618). Yenilikçilik, üretim faktörlerinin en önemli belirleyicilerinden biri olup işletmeye yeni kaynakların temin edilmesi 
ya da var olan kaynakların daha etkili şekilde kullanımına yönelik olarak değerlendirilebilir (Drucker, 2002).

\section{Yöntem}

Ekonometrik çalışmalarda genellikle ilgilenilen verilere göre doğru modelin belirlenmesi gerekmektedir. Değişken değerlerinin zaman birimlerine göre değişimini içeren veriler zaman serisi olarak tanımlanırken; zamanın belli bir noktasında farklı birimlerden toplanan veriler yatay kesit verisini ifade etmektedir. Çalışmanın amacına bağlı olarak bazı araştırmalarda (Akgün ve Akgün, 2016; Vurur ve İlarslan, 2016) sadece zaman boyutu ele alınırken bazı çalışmalarda (Lantz ve Sahut, 2005; Pabuçcu ve İmamoğlu, 2017) tek bir dönem için farklı birimler düşünülmektedir. Belirli bir dönem boyunca yatay kesit gözlemlerinin bir araya getirilmesi ile oluşturulan seriler ise panel veri seti olarak adlandırılmaktadır (Yerdelen Tatoğlu, 2013, s.2). Zaman ve yatay kesit gözlemlerini aynı anda içeren setler, karmaşık modellerin çözümlenmesini kolaylaştırmakta ve gözlenemeyen etkilerin daha iyi belirlenmesi sağlanmaktadır (Akça, 2018). Böylece ekonometrik verilere ilişkin daha güçlü tahminler gerçekleştirilebilmektedir.

$i$, yatay kesit birim sayısı ve $t$ ise zaman boyutu olmak üzere genel bir panel veri modeli aşağıdaki gibi ifade edilmektedir:

$$
Y_{i t}=\beta_{0 i t}+\beta_{1 i t} X_{1 i t}+\beta_{2 i t} X_{2 i t}+\cdots+\beta_{k i t} X_{k i t}+\varepsilon_{i t}
$$

Burada $Y$ bağımlı değişkeni, $X_{k}$ bağımsız değişkenleri, $\beta_{k}$ bağımsız değişkenlerin katsayılarını, $\beta_{0}$ sabit parametreyi ve $\varepsilon$ ise hata terimini göstermektedir. Hata terimlerinin birimlere ve zaman göre sıfir ortalama ve sabit varyans ile özdeş ve bağımsız normal dağıldığı varsayılmaktadır (Pazarlıŏlu ve Kiren Gürler, 2007, s.37; Yerdelen Tatoğlu, 2013, s.37).

Panel veri analizinde birimlerin ve/veya zamanın özelliklerine göre farklılık gösteren çeşitli modeller söz konusudur. Sabit ve eğim parametrelerinin birimlere ve zamana göre değişmediği klasik modellerde Havuzlanmış En Küçük Kareler (Pooled Least Squares- POLS) yöntemi ile tahminler gerçekleştirilmektedir. Ancak farklı birimler söz konusu olduğunda farklı zaman dönemleri için klasik modelde yer alan katsayılar farklı değerler alabilmektedirler. Bu durumda modelin tahmin edilmesi güçleşmektedir. $\mathrm{Bu}$ nedenle panel veri analizleri gerçekleştirilirken genellikle hata terimlerinin özelliklerine ve katsayıların değişebilir olmasına göre farklı modeller kullanılmaktadır (Pazarlığlu ve Kiren Gürler, 2007, s.37). Klasik modelin uygun olmadığı durumlarda birim ve/veya zaman etkilerin varsayımlarına göre ilgili modeller "Sabit Etkili Modeller" ya da "Tesadüfi Etkili Modeller" olarak adlandırılmaktadır. Araştırma modelinde gözlenemeyen birim etkiler hata terimi gibi tesadüfi bir değişken şeklinde ele alınıyorsa bu modeller tesadüfi etkili modeli fakat bu birim etkiler sabit bir parametre olarak düşünüldüğü takdirde bu modeller ise sabit etkili modeli oluşturmaktadır. Bu nedenle birim ve/veya zaman etkiler söz konusu olduğunda bu etkilerin sabit mi yoksa tesadüfi mi olduğunun belirlenmesi gerekmektedir (Yerdelen Tatoğlu, 2013, s.79).

\section{Araştırma Modeli}

Zhu ve Huang (2012), Apergis ve Sorros (2014), Kocamış ve Güngör (2014), Fındık ve Ocak (2016), Doğan ve Yıldız (2016), Yıldırım ve Sakarya (2017), Özer, Öztürk, Özer (2019), Taysı (2020) ile Sevim (2021) yaptıkları çalışmalarda, performans göstergesi ile ilgili Aktif Kârlılık Oranı (ROA) ve Özsermaye Kârlılık Oranı (ROE) değerlerini kullanmışlardır. Ayrıca işletmelerin yenilikçilik göstergesi olarak Zhu ve Huang (2012), Apergis ve Sorros (2014), Dağlı ve Ergün (2017), Demir ve Güleç (2018), Özer vd. (2019), Güzen ve Başar (2019) tarafından Ar-Ge giderleri dikkate alınmıştır. Literatürde yer alan çalışmalar göz önünde bulundurularak bu çalışmada ele alınan değişkenler Tablo 1'de sunulmaktadır: 
Tablo 1

Çalışmada Kullanılan Değişkenler ve Kısaltmaları

\begin{tabular}{|c|c|c|}
\hline Değişkenler & Değişken Açılklaması & Değişken Kısaltmast \\
\hline Bağımlı Değişkenler & & \\
\hline Aktif Kârlılık Oranı & Net Kâr/Toplam Kaynaklar & ROA \\
\hline Özsermaye Kârlılık Oranı & Net Kâr/Toplam Özkaynaklar & ROE \\
\hline Bağımsız Değişken & & \\
\hline Ar-Ge Gideri & İşletmelerin Ar-Ge harcamaları & ARGE \\
\hline $\begin{array}{l}\text { Kontrol Değişkeni } \\
\text { Kaldıraç Oran }\end{array}$ & Toplam Borç/Toplam Aktif & KLDRC \\
\hline
\end{tabular}

Tablo 1'de yer alan değişkenlere göre otomotiv imalat sektöründe yer alan 9 işletmenin finansal performansları üzerinde Ar-Ge harcamalarının etkisinin olup olmadığını belirlemek için

$$
\begin{aligned}
& \text { Model I: } R A O_{i t}=\beta_{0 i t}+\beta_{1 i t} A R G E+\beta_{2 i t} K L D R C+\varepsilon_{i t} \\
& \text { Model II:ROE } E_{i t}=\beta_{0 i t}+\beta_{1 i t} A R G E+\beta_{2 i t} K L D R C+\varepsilon_{i t}
\end{aligned}
$$

biçimindeki iki farklı ekonometrik model tanımlanmıştır. Burada Ar-Ge harcamalarının hem aktif kârlılık oranı hem de özsermaye kârlılık oranı üzerindeki etkisini belirlemek için iki farklı model dikkate alınmıştır. Ayrıca firmaların toplam borçlarının toplam aktiflere oranını ifade eden Kaldıraç Oranı (KLDRC) değişkeni ise araştırma modellerinin açıklama gücünü artırmak için kontrol değişkeni olarak analize dahil edilmiștir.

\section{Evren ve Örneklem}

Yenilikçiliğin finansal performans üzerinde etkisini belirlemek amacıyla Borsa İstanbul'da imalat sektörü içerisinde yer alan ve otomotiv alanında faaliyet gösteren işletmeler dikkate alınmıştır. Ancak faaliyet raporunda Ar-Ge harcaması bildiren 9 işletme analize dahil edilmiştir. Ayrıca bu çalışmada 2016Q1- 2020Q4 çeyrek dönemine ait toplam 20 dönem için ekonometrik analizler gerçekleştirilmiştir.

\section{Verilerin Toplanması ve Analizi}

Çalışmada işletmelere ait ekonometrik veriler, Kamuyu Aydınlatma Platformu (KAP) web sitesinde yer alan faaliyet raporlarından elde edilmiştir. Araştırma kapsamında incelemeye alınan işletmeler Tablo 2'de sunulmaktadır.

Tablo 2

Otomotiv İmalat Sektöründe Faaliyet Gösteren ve Çalışma Kapsamında İncelenen İşletmeler

\begin{tabular}{ll}
\hline Şirket & Hisse Kodu \\
\hline Anadolu Isuzu Otomotiv Sanayi ve Ticaret A.Ş. & (ASUZU) \\
Ditaş Doğan Yedek Parça İmalat ve Teknik A.Ş. & (DITAS) \\
Ege Endüstri ve Ticaret A.Ş. & (EGEEN) \\
Ford Otomotiv Sanayi A.Ş. & (FROTO) \\
Jantsa Jant Sanayi ve Ticaret A.Ş. & (JANTS) \\
Karsan Otomotiv Sanayi ve Ticaret A.Ş. & (KARSN) \\
Katmerciler Araç Üstü Ekipman Sanayi ve Ticaret A.Ş. & (KATMR) \\
Otokar Otomotiv ve Savunma Sanayi A.Ş. & (OTKAR) \\
Tofaş Türk Otomobil Fabrikası A.Ş. & (TOASO) \\
\hline
\end{tabular}

Çalışmada her bir işletmeye ait veriler bir araya getirilmiş ve araştırma modeli için panel veri analizi gerçekleştirilmiştir. Ekonometrik analizler için Stata 12.0 ve Eviews programları kullanılmıştır.

\section{Araştırma Etiği}

$\mathrm{Bu}$ çalışmada, analizde yer alan işletmelerin Kamuyu Aydınlatma Platformu (KAP) web sitesinde yer alan faaliyet raporları ve finansal tabloları kullanıldığı için etik kurul raporu alınmamıştır. 


\section{Bulgular}

Panel veri analizi, kesit ve zaman serisi verilerinin birlikte değerlendirildiği ekonometrik bir yöntemdir. Bu nedenle panel veri setleri için ekonometrik analizler gerçekleştirilmeden önce zaman serilerinde karşılaşılan problemlerin de dikkate alınması gerekmektedir. Zaman serisi analizlerinde değişkenler arasında anlamlı ilişkiler belirlenebilmesi için ilgilenilen serilerin durağan olması gerekmektedir. Durağan olmayan verilerin kullanılması, test istatistikleri ile elde edilen çözümlerin güvenilir olmamasına neden olmaktadır (Gujarati ve Porter, 1999, s.713). Bu nedenle panel veri analizlerinde ilk olarak serilerin durağan olup olmadığını belirlemek için birim kök testi gerçekleștirilmelidir. Ancak panel birim kök testleri, ilgilenilen birimler arasındaki ilişkilere bağlı olarak farklılık göstermektedir. Bu nedenle birim kök analizlerinden önce yatay kesit bağımlılı̆̆ının incelenmesi gerekmektedir.

\section{Yatay Kesit Bağımlılık Testi}

Paneli oluşturan yatay kesit birimlerinde meydana gelen etkilerin diğer birimleri de etkilemesi, yatay kesit bağımlılığı olarak tanımlanmaktadır. Panel veri setlerinde yatay kesit bağımlılığının olup olmadığını belirlemek için genellikle Breusch-Pagan (1980) CD $\mathrm{LM}_{\mathrm{LM}}$ testi, Pesaran (2004) $\mathrm{CD}_{\mathrm{LM} 2}$ ve CD testi ile Pesaran, Ullah ve Yamagata (2008) LMadj testi kullanılmaktadır. Birimler arasında ilişki olup olmadığını belirlemek için aşağıdaki hipotezler sınanmaktadır:

$H_{0}$ : Yatay kesit bağımlılı̆̆ yoktur.

$H_{1}$ : Yatay kesit bağımlılı̆̆ 1 vardır.

Yapılan test sonucunda elde edilen olasılık değerinin belirlenen anlam düzeyinden daha küçük olması durumunda $H_{0}$ hipotezi reddedilmekte ve yatay kesit verileri arasında bağımlılığın olduğuna karar verilmektedir. Araştırma modellerinde yer alan değişkenlere ait yatay kesit bağımlılık testi sonuçları aşağıda sunulmuştur.

Tablo 3

Değişkenler İçin Yatay Kesit Bă̆ımlılĭ̆ı Testi Sonuçları

\begin{tabular}{|c|c|c|c|c|c|c|c|c|}
\hline \multirow{2}{*}{$\begin{array}{l}\text { Yatay Kesit } \\
\text { Bağımlılığı } \\
\text { Testleri }\end{array}$} & \multicolumn{2}{|c|}{ ROA } & \multicolumn{2}{|c|}{ ROE } & \multicolumn{2}{|c|}{ ARGE } & \multicolumn{2}{|c|}{ KLDRC } \\
\hline & İstatistik & $\begin{array}{l}\text { Olasılık } \\
\text { Değeri }\end{array}$ & İstatistik & $\begin{array}{c}\text { Olasılık } \\
\text { Değeri }\end{array}$ & İstatistik & $\begin{array}{l}\text { Olasilık } \\
\text { Değeri }\end{array}$ & İstatistik & $\begin{array}{l}\text { Olasilık } \\
\text { Değeri }\end{array}$ \\
\hline $\begin{array}{l}\mathrm{CD}_{\mathrm{LM} 1} \\
(\mathrm{BP}, 1980)\end{array}$ & 107.12 & $<.001$ & 98.92 & $<.001$ & 103.33 & $<.001$ & 111.64 & $<.001$ \\
\hline $\begin{array}{l}\text { CD }_{\text {LM2 } 2} \text { (Pesaran } \\
2004 \text { ) }\end{array}$ & 8.38 & $<.001$ & 7.42 & $<.001$ & 7.94 & $<.001$ & 8.91 & $<.001$ \\
\hline $\begin{array}{l}\text { CD(Pesaran } \\
2004)\end{array}$ & 8.15 & $<.001$ & 7.18 & $<.001$ & 7.70 & $<.001$ & 8.68 & $<.001$ \\
\hline $\begin{array}{l}\text { LM }_{\text {adj }} \text { (Pesaran } \\
\text { vd. 2008) }\end{array}$ & 5.33 & $<.001$ & 5.14 & $<.001$ & 6.82 & $<.001$ & 3.66 & $<.001$ \\
\hline
\end{tabular}

Tablo 3 incelendiğinde değişkenler için yatay kesit bağımlılığ 1 test istatistiklerine göre olasılık değerlerinin 0.05 'ten daha küçüktür. Buna göre yokluk hipotezi reddedilmiştir ve $\% 5$ anlamlılık düzeyinde yatay kesit bağımlılı̆̆ı olduğuna karar verilmiştir.

\section{Panel Birim Kök Testi}

Panel veri setleri kullanılarak yapılan ekonometrik araştırmalarda serilerin durağan olup olmadığının belirlenmesi gerekmektedir. Ancak durağanlık sınamasını belirlemek için kullanılan birim kök testleri, birim arasındaki yatay kesit bağımlılığına göre birinci ve ikinci nesil birim kök testleri olarak ikiye ayrılmaktadır. Yatay kesit bağımlılı̆̆ının olmadığı durumlarda birinci nesil panel birim kök testlerinden yararlanılmaktadır. Ancak kesit verileri arasında bağımlılık söz konusu olduğunda ise birinci nesil panel birim kök testleri hatalı sonuçlar vermektedir. Bu nedenle yatay kesit bağımlılı̆̆ını da dikkate alan ikinci nesil testler kullanılmaktadır. 
Çalışmada ele alınan değişkenler için yatay kesit bağımlılı̆̆ söz konusu olması nedeniyle Pesaran (2007) tarafindan önerilen CADF (Cross-Sectionally Augemented Dickey-Fuller) ve CIPS (Cross-Sectional Augmented IPS) test istatistikleri kullanılmıştır. CADF testi, yatay kesit birimleri için ayrı ayrı birim kök sınaması yapılabilmektedir. CIPS testi ise panelin tümü için her bir kesite ait CADF test istatistiklerinin ortalamasını göstermektedir. Panel birim kök testinde aşağıdaki hipotezler sinanmaktadır:

$$
\begin{aligned}
& H_{0} \text { : Seri durağan değildir. } \\
& H_{1} \text { : Seri durağandır. }
\end{aligned}
$$

CADF ve CIPS test istatistikleri Pesaran (2007) kritik tablo değerlerinden mutlak değer olarak daha büyük ise yokluk hipotezi reddedilmekte ve serilerin durağan olduğu söylenebilmektedir (Pesaran, 2007, ss.274-276; Temelli ve Şahin, 2019, s.585). Ekonometrik modelde yer alan bütün göstergeler için elde edilen birim kök test sonuçları Tablo 4’te sunulmaktadır:

Tablo 4

CIPS Panel Birim Kök Testi Sonuçları

\begin{tabular}{ccccccccc}
\hline & \multicolumn{3}{c}{ Sabitli } & \multicolumn{3}{c}{ Sabitsizve Trendsiz } \\
\hline & $\begin{array}{c}\text { Test } \\
\text { Istatistiği }\end{array}$ & $\mathbf{\% 1 0}$ & $\mathbf{\% 5}$ & $\mathbf{\% 1}$ & $\begin{array}{c}\text { Test } \\
\text { Istatistiğ } \boldsymbol{i}\end{array}$ & $\mathbf{\% 1 0}$ & $\mathbf{\% 5}$ & $\mathbf{\% 1}$ \\
\hline ROA & $-2.755^{*}$ & -2.21 & -2.34 & -2.60 & $-2.317^{*}$ & -1.58 & -1.72 & -2.00 \\
ROE & $-2.526^{* *}$ & -2.21 & -2.34 & -2.60 & $-1.832^{* *}$ & -1.58 & -1.72 & -2.00 \\
ARGE & $-2.455^{* *}$ & -2.21 & -2.34 & -2.60 & $-2.404^{* *}$ & -1.58 & -1.72 & -2.00 \\
KLDRC & -1.414 & -2.21 & -2.34 & -2.60 & $-1.590^{* * *}$ & -1.58 & -1.72 & -2.00 \\
\hline
\end{tabular}

Maksimum gecikme uzunluğu 4 olarak alınmıştır. Tablodaki kritik değerler, Pesaran (2007: 279-280) tarafindan oluşturulan Tablo II (a) ve Tablo II (b)'den elde edilmiştir.

Tablo 4 incelendiğinde hem sabitli hem de sabitsiz ve trendsiz model için ROA değişkenine ait CIPS test istatistiği, \%1 anlamlılık düzeyinde mutlak değer olarak Pesaran (2007) tablo değerinden daha yüksek bulunmuştur. Benzer şekilde ROE ve ARGE değişkenlerine ait CIPS test istatistiklerinin de mutlak değerce $\% 5$ anlamlılık düzeyinde tablo değerinden daha büyük olduğu görülmüştür. KLDRC değişkeni ise sabitsiz ve trendsiz model için \%10 önem düzeyinde anlamlı olarak elde edilmiştir. $\mathrm{Bu}$ durumda CIPS test istatistikleri Pesaran (2007) kritik değerleri ile karşılaștırıldığında test istatistiklerinin mutlak değerce $\% 1, \% 5$ ve \%10 önem düzeyinde anlamlı olduğu ve serilerin durağan olduğu belirlenmiştir.

\section{Panel Veri Modelinin Belirlenmesi}

Doğrusal panel veri modellerinde birimlere ve/veya zamana göre değişen parametreler için çeşitli tahmin yöntemleri önerilmiştir. Ancak tahmin yönteminin doğru belirlenmesi için araştırma problemini temsil eden ekonometrik modele karar verilmesi gerekmektedir. Panel veri analizinde birim ve/veya zaman etkilerinin olup olmadığını sınamak için genellikle $F$ testi kullanılmaktadır. $F$ testi için "Birim ve zaman etki yoktur" şeklinde ifade edilen yokluk hipotezi sınanmakta ve test istatistiği değeri $F$ tablo değeri ile karşılaştırılmaktadır (Taysı, 2020, s.23). İşletme performansı ile Ar-Ge harcamaları arasındaki ilişkiyi temsil eden ekonometrik modeller için uygulanan $F$ testi sonuçları Tablo 5 'te gösterilmektedir:

Tablo 5

Klasik Modelin Uygunluğunu Belirlemek İçin Uygulanan F Testi Sonuçları

\begin{tabular}{ccc}
\hline & $\boldsymbol{F}$ Test İstatistĭg & Olasillk Değeri \\
\hline Model I & 9.72 & $<.001$ \\
Model II & 6.97 & $<.001$ \\
\hline
\end{tabular}

Tablo 5'te yer alan $F$ testi sonuçları incelendiğinde her iki model için elde edilen olasılık değerlerinin 0.05 'ten küçük olduğu görülmüştür. Buna göre $\% 5$ anlamlılık düzeyinde modeller için 
yokluk hipotezi reddedilmiştir. Böylece eğim parametresi ile sabit parametrenin birimlere ve zamana göre sabit olduğu klasik modelin uygun olmadığına karar verilmiştir.

Yapılan $F$ testi sonucuna göre birim ve/veya zaman etkilerinin var olduğu tespit edilmiştir. Ancak belirlenen bu etkilerin sabit ya da tesadüfi olduğuna karar vermek gerekmektedir. Bu amaçla tahminciler arasında seçim yapmak için Hausman (1978) tarafindan geliştirilen ve tesadüfi etkiler modeline karşı sabit etkiler modelini sınayan Hausman testi kullanılmaktadır (Uluyol ve Türk, 2013, s.377). Hausman testinde aşağıdaki hipotezler sınanmaktadır:

$H_{0}$ : Tesadüfi etkiler modeli geçerlidir.

$H_{1}$ : Sabit etkiler modeli geçerlidir.

Belirlenen $\alpha$ anlamlılık düzeyine göre yokluk hipotezi kabul edildiğinde tesadüfi etkiler modelinin uygun olduğuna karar verilmektedir. Ancak yokluk hipotezi reddedildiğinde sabit etkiler modelinin geçerli olduğu ifade edilmektedir. Çalışmada kurulan modellere ait doğru tahmin yöntemine karar vermek için Hausman testi uygulanmış ve test sonuçları Tablo 6'da gösterilmiştir.

Tablo 6

Hausman Testi Sonuçları

\begin{tabular}{ccc}
\hline & $\chi^{2}$ Test İstatistiği & Olasillk Dĕgeri \\
\hline Model I & 0.060 & 0.8091 \\
Model II & 5.28 & 0.0216 \\
\hline
\end{tabular}

Tablo 6 incelendiğinde birinci model için olasıllık değerlerinin 0.05 'ten daha büyük olduğu görülmektedir. Böylece ROA göstergesinin bağımlı değişken olarak incelendiği Model I için yokluk hipotezi reddedilememiştir. Bu durumda tesadüfi etkiler modelinin uygun olduğuna karar verilmiştir. Model II için uygulanan Hausman testi sonucunda ise olasılık değerinin 0.05 'ten daha küçük olduğu görülmüş ve yokluk hipotezi reddedilmiştir. Dolayısıyla Model II için birim ve/veya zaman etkilerin bir sabit olduğu görülmüş ve sabit etkiler modelinin geçerli olduğu belirlenmiştir. Bu durumda sabit etkiler modelinin varsayımlarının test edilmesi gerekmektedir.

\section{Model Varsayımlarının Test Edilmesi}

Birim ve zaman etkilerine göre farkl11ık gösteren modeller belirlendikten sonra bu modellere ilişkin katsayılar tahmin edilebilmektedir. Ancak sabit etkiler ve tesadüfi etkiler modeli için temel varsayımların sağlanması gerekmektedir. Sabit etkiler ve tesadüfi etkiler modelinde hata terimlerinin sabit varyanslı olmas1, otokorelasyon olmamas1 ve birimler arası korelasyonsuz olması beklenmektedir. Hata terimlerinin birimler içerisinde ve birimler arasında ilişkili olması sırasıyla otokorelasyon ve birimler arası korelasyon kavramları ile ifade edilmektedir. Bu varsayımlardan en az biri sağlanmadığında birim matris özelliğine sahip olan varyans-kovaryans matrisleri bu özelliğini kaybetmektedir (Yerdelen Tatoğlu, 2013, s.197). Bu nedenle belirlenen modellerin anlamlı sonuçlar ortaya koyabilmesi için varsayımların karşılanması gerekmektedir. Bu varsayımlar sağlandığı takdirde sabit etkiler ve tesadüfi etkiler modelleri için uygun olan tahminciler kullanılmaktadır. Ancak varsayımların karşılanmadığı durumlarda varsayım ihlallerine karşı daha dayanıklı olan tahmin yöntemleri dikkate alınmaktadır.

Hata terimlerindeki varyansların sabit olup olmadığını belirlemek için tesadüfi etkiler modelinde Levene-Brown ve Forsythe test istatistiği ve sabit etkiler modelinde ise Değiştirilmiş Wald test istatistiği kullanılmıştır. Otokorelasyon problemini tespit etmek amacıyla her iki model için Bhargawa, Franzini ve Narendranathan (1982) Durbin-Watson testi ile Baltagi - Wu (1999) Yerel En İyi Değişmez testinden yararlanılmıştır. Son olarak birimler arası korelasyon varlığını araştırmak için Friedman (1937) ve Pesaran (2004) testleri dikkate alınmıştır. Sabit ve tesadüfi etkiler modelleri için sabit varyans, otokorelasyon ve birimler arası korelasyon varsayımların sağlanıp sağlanmadığını tespit etmek amaciyla her bir varsayım testine ait yokluk hipotezleri ve test istatistikleri Tablo 7'de görülmektedir. 
Model I için uygulanan Levene-Brown ve Forsythe'nin (2002) test istatistikleri (W0, W50, W10), $(8,171)$ serbestlik dereceli $F$ tablo değeri ile karşılaştırılmıştır. Model II için uygulanan Değiştirilmiş Wald test istatistiği olasılık değerleri ise 0.05 'ten daha küçük olarak elde edilmiştir. Dolayısıyla her iki model için "Hata terimlerinin varyansları eşittir" biçimindeki yokluk hipotezi reddedilmiş ve hata terimlerinin sabit varyanslı olmadığına karar verilmiştir. Birimler arası korelasyon varlığını araştırmak için uygulanan Pesaran ve Friedman test istatistiklerinin sonuçları da her iki model için $\% 5$ anlamlllık düzeyinde yokluk hipotezinin reddedildiğini göstermiştir. Bu durumda hem sabit etkiler hem de tesadüfi etkiler modeli için birimler arası ilişkisizlik özelliğinin sağlanmadığı belirlenmiştir.

Tablo 7

Araştırma Modelleri İçin Sabit Varyans, Otokorelasyon ve Birimler Arası Korelasyon Varsayımları Test Sonuçları

\begin{tabular}{|c|c|c|c|}
\hline \multicolumn{4}{|c|}{ Heteroskedasite (Sabit Varyans) } \\
\hline \multicolumn{2}{|c|}{$\begin{array}{l}\text { Model I: } R O A_{i t}=\beta_{0 i t}+\beta_{1 i t} A R G E+\beta_{2 i t} K L D R C+ \\
\varepsilon_{i t}\end{array}$} & \multicolumn{2}{|c|}{$\begin{array}{l}\text { Model II: } R O E_{i t}=\beta_{0 i t}+\beta_{1 i t} A R G E+ \\
\beta_{2 i t} K L D R C+\varepsilon_{i t}\end{array}$} \\
\hline \multicolumn{4}{|c|}{$H_{0}:$ Hata terimlerinin varyansları eşittir. } \\
\hline Levene-Brown ve Forsythe' & in (2002) Test İstatistiği & $\begin{array}{c}\text { Değişstirilmiş Wald Test } \\
\dot{\text { Istatistiği }}\end{array}$ & Olasılık Değeri \\
\hline \multicolumn{4}{|c|}{$\mathrm{W} 0=5.8619328 \mathrm{df}(8,171) \mathrm{Pr}>\mathrm{F}=0.00000127$} \\
\hline $\mathrm{W} 50=4.3511013 \mathrm{df}(8,17$ & $\mathrm{Pr}>\mathrm{F}=0.00008477$ & 657.83 & $<.001$ \\
\hline \multicolumn{4}{|c|}{$\mathrm{W} 10=4.9413652 \mathrm{df}(8,171) \operatorname{Pr}>\mathrm{F}=0.00001633$} \\
\hline \multicolumn{4}{|c|}{ Otokorelasyon } \\
\hline \multicolumn{2}{|c|}{$\begin{array}{l}\text { Model I: } R O A_{i t}=\beta_{0 i t}+\beta_{1 i t} A R G E+\beta_{2 i t} K L D R C+ \\
\varepsilon_{i t}\end{array}$} & \multicolumn{2}{|c|}{$\begin{array}{l}\text { Model II: } R O E_{i t}=\beta_{0 i t}+\beta_{1 i t} A R G E+ \\
\beta_{2 i t} K L D R C+\varepsilon_{i t}\end{array}$} \\
\hline \multicolumn{4}{|c|}{$H_{0}:$ Hata terimleri arasında otokorelasyon yoktur. } \\
\hline $\begin{array}{c}\text { Bhargawa, Franzini ve } \\
\text { Narendranathan Durbin- } \\
\text { Watson Test İstatistiği }\end{array}$ & $\begin{array}{c}\text { Baltagi-Wu Yerel En } \\
\text { Iyi Değişmez Test } \\
\text { Istatistiği }\end{array}$ & $\begin{array}{l}\text { Bhargawa, Franzini ve } \\
\text { Narendranathan Durbin- } \\
\text { Watson Test İstatistiği }\end{array}$ & $\begin{array}{c}\text { Baltagi - Wu Yerel } \\
\text { En İyi Değişmez Test } \\
\text { İstatistiği }\end{array}$ \\
\hline 1.2680975 & 1.3506934 & 1.7991871 & 1.8535477 \\
\hline \multicolumn{4}{|c|}{ Birimler Arası Otokorelasyon } \\
\hline \multicolumn{2}{|c|}{$\begin{array}{l}\text { Model I: } R O A_{i t}=\beta_{0 i t}+\beta_{1 i t} A R G E+\beta_{2 i t} K L D R C+ \\
\varepsilon_{i t}\end{array}$} & \multicolumn{2}{|c|}{$\begin{array}{l}\text { Model II: } R O E_{i t}=\beta_{0 i t}+\beta_{1 i t} A R G E+ \\
\beta_{2 i t} K L D R C+\varepsilon_{i t}\end{array}$} \\
\hline \multicolumn{4}{|c|}{$H_{0}:$ Birimler arası otokorelasyon yoktur. } \\
\hline Pesaran Test İstatistiğ $i$ & Olasılık Değeri & Pesaran Test İstatistiğ $i$ & Olasılık Değeri \\
\hline 5.453 & $<.001$ & 4.411 & $<.001$ \\
\hline Friedman Test İstatistiğ $i$ & Olasılık Değeri & Friedman Test İstatistiğ $i$ & Olasılık Değeri \\
\hline 50.352 & $<.001$ & 46.556 & $<.001$ \\
\hline
\end{tabular}

Bhargawa, Franzini ve Narendranathan (1982) Durbin-Watson ve Baltagi - Wu (1999) Yerel En İyi Değişmez testi istatistikleri 2'den küçük olduğunda otokorelasyon önemli olarak yorumlanmaktadır (Yerdelen Tatoğlu, 2013, s.214). Bhargawa, Franzini ve Narendranathan DurbinWatson testi ve Baltagi - Wu Yerel En İyi Değişmez test istatistikleri incelendiğinde her iki değerin 2 'den daha küçük olduğu görülmektedir. Bu durum ilgilenilen modeller için hata terimleri arasında önemli derecede otokorelasyon olduğunu göstermektedir. Tüm sonuçlar dikkate alındığında hem sabit hem de tesadüfi etkiler modelinin katsayılarını tahmin etmek için gerekli varsayımların sağlanmadığı gözlemlenmiştir.

\section{Modelin Tahmin Edilmesi}

Değişen varyans, otokorelasyon ve birimler arası korelasyon varsayımlarının incelendiği her iki model için bu varsayımların karşılanmadığı gözlemlenmiştir. Bu durumda yapılacak parametre tahminleri için varsayımların ihlallerine göre uygun tahmin yöntemlerinin kullanılması gerekmektedir. Model I için değişen varyans, otokorelasyon ve birimler arası korelasyon olması nedeniyle AR (1) 
kalıntılı tesadüfi etkiler modeli tahmin edilmiştir. AR (1) kalıntılı tesadüfi etkiler modeline göre elde edilen tahmin sonuçları Tablo 8'de verilmiştir:

Tablo 8

AR (1) Kalıntılı Tesadüfi Etkiler Modeli Tahmin Sonuçları

\begin{tabular}{|c|c|c|c|c|}
\hline ROA & Katsayt & Standart hata & t değeri & Olasılık Değeri \\
\hline ARGE & $3.18 \mathrm{e}-10$ & $1.18 \mathrm{e}-10$ & 2.70 & .007 \\
\hline KLDRC & -0.126667 & 0.0197295 & -6.42 & $<.001$ \\
\hline Sabit & 0.1030079 & 0.0137234 & 7.51 & $<.001$ \\
\hline
\end{tabular}

Wald $\chi^{2}$ dĕgeri: 41.22

Olasılık Değeri: $<.001$

$R^{2}: 0.5068$

Model I için AR (1) kalıntılı tesadüfi etkiler tahmininde elde edilen olasılık değeri $(<.001)$ incelendiğinde oluşturulan modelin genel olarak anlamlı olduğu görülmektedir. Tablo 8'e göre elde edilen panel veri modeli

$$
R O A=0.1030079+(3.18 e-10 * A R G E)-(0.126667 * K L D R C)
$$

biçimindedir. ROA ile bütün değişkenler arasında \%5 anlamlllık düzeyinde istatistiksel olarak anlamlı bir ilişki olduğu belirlenmiştir. Ar-Ge harcamalarının aktif kârlılık oranı üzerinde pozitif bir etkisi söz konusu iken kontrol değişkeni olarak modele dahil edilen kaldıraç oranının ise negatif bir etkisi olduğu gözlemlenmiştir. Ayrıca $\mathrm{R}^{2}$ değeri de 0.5068 olarak elde edilmiştir. Bu sonuç ROA üzerindeki değişikliğin yaklaşık \%51'inin ARGE ve KLDRC değişkenleri tarafından açıklandığını göstermektedir.

Değişen varyans, otokorelasyon ve birimler arası korelasyon varsayımlarının sağlanmadığı sabit etkiler modelinde ise model parametrelerini tahmin etmek için Driscroll ve Kraay (1998) tarafindan geliştirilen tahmin yöntemi kullanılmıştır.

Tablo 9

Driscroll ve Kraay (1998) Tahmin Sonuçları

\begin{tabular}{ccccc}
\hline ROE & Katsayl & Robust standart hata değerleri & t değeri & Olasilık Değeri \\
\hline ARGE & $2.09 \mathrm{e}-09$ & $5.54 \mathrm{e}-10$ & 3.78 & .005 \\
KLDRC & -0.5195384 & 0.1846263 & -2.81 & .023 \\
Sabit & 0.83670187 & 0.1207718 & 3.04 & .016 \\
\hline
\end{tabular}

F değeri: 8.80

Olasilık Değeri: .0095

$R^{2}: 0.1088$

Driscroll ve Kraay (1998) dirençli tahmin yöntemi sonuçlarına göre Model II için tahmin edilen $F$ değeri (8.80) ile bu değere ilişkin olasıllı değeri incelendiğinde, oluşturulan modelin genel olarak anlamlı olduğu görülmektedir. Ayrıca Tablo 9'a göre elde edilen panel veri modeli aşağıdaki gibi ifade edilebilmektedir:

$$
R O E=0.83670187+(2.09 \mathrm{e}-09 * A R G E)-(0.5195384 * K L D R C)
$$

Modele göre ROE ile bütün değişkenler arasında \%5 anlamlılık düzeyinde istatistiksel olarak anlamlı bir ilişki olduğu belirlenmiştir. Aktif kârlılık oranına paralel olarak özsermaye kârlılık oranı üzerinde Ar-Ge harcamalarının pozitif ve kaldıraç oranının negatif bir etkisi olduğu gözlemlenmiştir. Ayrıca $\mathrm{R}^{2}$ değerine göre ROE üzerindeki değişikliğin yaklaşık \%11'inin ARGE ve KLDRC değişkenleri tarafından açıklandığını göstermektedir. Böylece her iki modelden elde edilen sonuçlara göre çalışmada ele alınan 9 şirket için Ar-Ge yatırımlarının, finansal performansları üzerinde pozitif bir etki ortaya koyduğu söylenebilmektedir. 


\section{Sonuç, Tartışma ve Öneriler}

Küresel rekabet ortamında işletmelerin varlıklarını sürdürebilmeleri performanslarını artırmalarına bağlıdır. Yenilikçilik konusunda başarılı olan işletmelerin finansal performanslarının da artacağ 1 düşünülmektedir. Bu çalışmanın amacı, otomotiv imalat sektöründeki işletmelerin Ar-Ge harcamalarının finansal performansları üzerindeki etkisinin belirlenmesidir. Bu doğrultuda, BİST 100 endeksinde yer alan ve faaliyet raporunda Ar-Ge harcaması bildiren 9 işletmenin 2016Q1-2020Q4 dönemine ait verileri incelenmiştir. Literatürde yer alan çalışmalar göz önünde bulundurularak şirketlerin finansal performans göstergesi için Aktif Kârlılık Oranı (ROA) ile Özsermaye Kârlılık Oranı (ROE) değerleri dikkate alınmıştır. Ayrıca şirketlerin Ar-Ge yatırımlarını temsil etmesi amacıyla faaliyet giderleri içerisinde yer alan Ar-Ge harcamaları (ARGE) kullanılmıştır.

ROA ve ROE bağımlı değişkenlerine göre oluşturulan iki ayrı model için birim ve/veya zaman etkilerin olup olmadığ araştırılmış ve her iki model için birim ve/veya zaman etkilerin olduğuna karar verilmiştir. $\mathrm{Bu}$ etkilerin sabit mi yoksa tesadüfi mi olduğuna karar vermek için Hausman testi uygulanmıştır. Uygulanan test sonucunda ROA değişkenin bağımlı değişken olduğu Model I için tesadüfi etkiler modelinin uygun olduğuna karar verilirken ROE göstergesine dayalı olarak oluşturulan Model II'nin ise sabit etkiler modeline uygunluğu belirlenmiştir. Model parametrelerinin tahminin de sabit varyanslılık, otokorelasyonsuzluk ve birimler arası korelasyonsuzluk özellikleri incelenmiş ve araştırma modelleri için varsayımların karşılanmadığı gözlemlenmiştir. $\mathrm{Bu}$ durumda model parametrelerinin tahmin edilmesi için varsayım ihlallerini dikkate alan modeller kullanılmıştır.

İşletmelerin finansal performansı üzerindeki Ar-Ge yatırımlarının etkisini belirlemek amacıyla oluşturulan her iki model için ARGE ile ROA ve ROE arasında anlamlı ve pozitif bir ilişkinin varlığı gözlemlenmiştir. Yani yapılan araştırma ve geliştirme yatırımları, işletmelerin aktif kârlılık oranları ile özsermaye kârlılık oranlarını arttırdığını göstermektedir. Bu çalışmanın sonuçları; Han, Kim ve Srivastava (1998), Orfila-Sintes ve Mattsson (2009), Apergis ve Sorgis (2014), Öncü, Bayat, Kethüda ve Zengin (2015), Doğan ve Yıldız (2016), Dağlı ve Ergün (2017), Gürkan ve Gürkan (2017) ile Yıldırım ve Sakarya (2017) başta olmak üzere Ar-Ge harcamalarının finansal performans üzerindeki etkisini araştıran birçok çalışmanın sonuçları ile benzerlik göstermektedir. Çalışmada kullanılan verilerin güncel verilerden oluşturulması ve analizin inovasyona açık bir sektör olan otomotiv sektörü üzerinde gerçekleştirilmesi nedeniyle literatüre katkı sağladığı kabul edilebilir. Daha sonra yapılacak çalışmalarda analize değişik sektörlerde yer alan işletmelerin dahil edilmesi ve analize dahil edilecek değişken sayısının arttırılması ile daha farklı sonuçlar elde edilebilecektir.

\section{Araştırmacıların Katkı Oranı}

Bu makaleye birinci yazarın $\% 50$, ikinci yazarın $\% 50$ oranında katkısı vardır.

\section{Çıkar Çatışması}

Çıkar çatışması teşkil edebilecek bir durum yoktur.

Teşekkür ve/veya Açılama: Bu çalı̧̧ma, 10. Uluslararası Girişimcilik Kongresi’nde özet bildiri olarak sunulmuştur (ICE-2019).

\section{Kaynaklar}

A $\breve{g c a}$, V. ve Kandemir, T. (2008). Aile işletmelerinde iç girişimcilik finansal performans ilişkisi: Afyonkarahisar'da bir araştırma. Afyon Kocatepe Üniversitesi Sosyal Bilimler Dergisi, 10(3), 209-230.

Akal, Z. (2005). İşletmelerde performans ölçüm ve denetimi çok yönlü performans göstergeleri. Ankara: MPM Yayincilik. 
Akça, H. S. (2018). Ekonomik Büyüme ve İnovasyon İlişkisi: Seçilmiş OECD Ülkeleri Üzerine Panel Veri Analizi. Yüksek Lisans Tezi, KTO Karatay Üniversitesi, Sosyal Bilimler Enstitüsü, Konya.

Akgün, A. ve Akgün, V. Ö. (2016). İşletmelerde Ar-Ge harcamalarının kârlılı̆̆a etkisi: Aselsan örneği. Selçuk Üniversitesi Sosyal ve Teknik Araştırmalar Dergisi, 12, 1-12.

Apergis, N. and Sorros, J. (2014). The Role of R\&D expenses for profitability: evidence from U.S. fossil and renewable energy firms. International Journal of Economics and Finance, 6(3), 8-15.

Aytekin, S. ve Özçalık Güler, S. (2018). Borsa İstanbul teknoloji ve bilişim endeksi firmalarında Ar-Ge harcamaları ve finansal performans ilişkisi. Anemon Muş Alparslan Üniversitesi Sosyal Bilimler Dergisi, 6(18): 67-73.

Aytekin, S. ve Sakarya, Ş. (2013). BİST'de işlem gören gıda işletmelerinin TOPSIS yöntemi ile finansal performanslarının değerlendirilmesi. Yönetim ve Ekonomi Araştırmaları Dergisi, 11(21), 30-47.

Baltagi, B. H. and Wu, P. X. (1999). Unequally spaced panel data regressions with AR (1) disturbances. Econometric Theory, 15(6), 814-823.

Bhargava, A., Franzini, L. and Narendranathan, W. (1982). Serial correlation and the fixed effects model. The Review of Economic Studies, 49(4), 533-549.

Bolat, T. (2005). Toplam kalite yönetimi: konaklama işletmelerinde uygulaması. İstanbul: Beta Yayınc1lik.

Breusch, T. S. and Pagan, A. R. (1980). The Lagrange Multiplier test and its applications to model specification in Econometrics. The Review of Economic Studies, 47(1), 239-253.

Çiçek, H. ve Onat, O. K. (2012). İnovasyon odaklı faaliyetlerin firma performansına etkisinin veri zarflama analizi ile belirlenmesi; IMKB üzerine bir araştırma. Mehmet Akif Ersoy Üniversitesi Sosyal Bilimler Enstitüsü Dergisi, 4(7), 46-53.

Cho, H. J. and Pucik, V. (2005). Relationship between innovativeness, quality, growth, profitability, and market value. Strategic Management Journal, 26(6), 555-575.

Dağlı, H. ve Ergün, T. (2017). Türkiye'de AR-GE harcamalarının firma kârlılığına etkisi. Karadeniz Teknik Üniversitesi Sosyal Bilimler Enstitüsü Sosyal Bilimler Dergisi, 7(13), 69-83.

Damanpour, F. (1991). Organizational innovation: a meta-analysis of effects of determinants and moderators. The Academy of Management Journal, 34(3), 555-590.

Demir, C. ve Güleç, Ö. (2019). Araştırma ve geliştirme giderlerinin firma kârlılığı üzerine etkisi: BIST imalat sektörü örneği. Pamukkale Üniversitesi Sosyal Bilimler Enstitüsü Dergisi, 34, 57-72.

Doğan, M. ve Yıldız, F. (2016). Araştırma ve geliştirme harcamalarının (Ar-Ge) firma kârlıı̆ı̆ı üzerindeki etkisi: BISST'te ișlem gören imalat sanayi firmaları üzerine bir araștırma. Kastamonu Üniversitesi İktisadi ve İdari Bilimler Fakültesi Dergisi, 14(4), 178-187.

Driscoll, J. C. and Kraay, A. C. (1998). Consistent covariance matrix estimation with spatially dependent panel data. Review of Economics and Statistics, 80(4), 549-560.

Drucker, P. (2002). The discipline of innovation. Retrieved from https://hbr.org/2002/08/the-disciplineof-innovation in 16.03.2021.

Fındık, D. ve Ocak, M. (2016). Türkiye'de maddi olmayan varlık yatırımlarının işletmelerin finansal performansı üzerine etkisi. Ege Akademik Bakış, 16(3), 397-414. 
Friedman, M. (1937). The use of ranks to avoid the assumption of normality implicit in the analysis of variance. Journal of the American Statistical Association, 32(200), 675-701.

Geroski, P. A. (1995). Innovation and competitive advantage. Retrieved from https://doi.org/10.1787/344434438114 in 16.03.2021.

Gujarati, D. N. and Porter, D. C. (1999). Basic econometrics, New York: McGraw-Hill.

Gürkan, N. ve Gürkan, S. (2017). Yenilikçilik kavramının işletmelerin finansal performansı üzerindeki etkisi. Uluslararası Yönetim İktisat ve Iş̧letme Dergisi, 13(13), 213-226.

Güzen, H. ve Başar, B. (2019). AR-GE harcamalarının raporlanması ve kârlılığa etkisi: BİST sınai endeksi işletmeleri üzerine bir araştırma. Anadolu Üniversitesi İktisadi ve İdari Bilimler Fakültesi Dergisi, 20(2), 1-24.

Han, J. K., Kim, N. and Srivastava, R. K. (1998). Market orientation and organizational performance: 1s innovation a missing link?. Journal of Marketing, 62(4), 30-45.

Hausman, J. A. (1978). Specification tests in Econometrics. Econometrica, 46(6), 1251-1271.

Kavak, Ç. (2009, 11-13 Şubat). Bilgi ekonomisinde inovasyon kavramı ve temel göstergeleri. Akademik Bilişim'09 - XI. Akademik Bilişim Konferansı Bildirileri, Harran Üniversitesi, Şanlıurfa. https://ab.org.tr/ab09/kitap/kavak_inovasyon_AB09.pdf adresinden 15.03.2021 tarihinde erişilmiştir.

Kiracı, K. (2019). BİST turizm endeksi ile dolar kuru, dolar endeksi ve petrol fiyatları arasındaki nedensellik ilişkisinin ampirik analizi. Erciyes Üniversitesi İktisadi ve İdari Bilimler Fakültesi Dergisi, 53, 73-86.

Kocamış, U.T. ve Güngör, A. (2014). Türkiye'de Ar-Ge harcamaları ve teknoloji sektöründe Ar-Ge giderlerinin kârlılık üzerine etkisi: Borsa İstanbul uygulaması. Maliye Dergisi, 166, 127-138.

Lantz, J. S. and Sahut, J. M. (2005). R\&D investment and the financial performance of technological firms. International Journal of Business, 10(4), 2-20.

Saliba de Oliviera J. A., Cruz Basso, L. F., Kimura, H. and Sobreiro, V. A. (2018). Innovation and financial performance of companies doing business in Brazil. International Journal of Innovation Studies, 2(4), 153-164.

Orfila-Sintes, F. and Mattsson, J. (2009). Innovation behavior in the hotel industry. Omega, 37(2), 380394.

Öncü, M. A., Bayat, M., Kethüda, Ö. ve Zengin, E. (2015). Yenilik ve müssteri performansının finansal performans üzerindeki etkisi: Orta ölçekli sanayi işletmelerinde bir araştırma. Marmara Üniversitesi IIBF Dergisi, 37(1), 149-164.

Özer, A., Öztürk, M. ve Özer, N. (2019). BİST imalat sanayi firmalarının araştırma ve geliştirme giderlerinin piyasa değeri ve firma kârlılı̆̆ üzerindeki etkisi. Muhasebe ve Finansman Dergisi, $82,135-146$.

Pabuçcu, H. ve İmamoğlu, İ. K. (2017). Yeniliğin belirleyicileri: yatay kesit veri analizi. Gazi Üniversitesi İktisadi ve İdari Bilimler Fakültesi Dergisi, 19(1), 110-129.

Pazarlığlu, M. V. ve Kiren Gürler, Ö. (2007). Telekomünikasyon yatırımları ve ekonomik büyüme: panel veri yaklaşımı. Finans Politik And Ekonomik Yorumlar, 44(508), 35-43. 
Pesaran, M.H. (2004). General diagnostic tests for cross section dependence in panels (Cambridge Working Papers in Economics). Retrieved from http://ftp.iza.org/dp1240.pdf in 20.03.2021.

Pesaran, M. H. (2007), A simple panel unit root test in the presence of cross-section dependence. Journal of Applied Econometrics, 22(2), 265-312.

Pesaran, M. H., Ullah, A. and Yamagata, T. (2008). A Bias-Adjusted LM test of error cross-section independence. Econometrics Journal, 11(1), 105-127.

Schumpeter, J. A. (1934). The theory of economic development. Massachusetts: Harvard University Press.

Sevim, U. (2021). İşletmelerin çevresel yatırım harcamalarının finansal performans üzerine etkisi: BİST sürdürülebilirlik endeksi üzerine bir araştırma. Gazi İktisat ve İsletme Dergisi, 7(1), 55-67.

Şişmanoğlu, E. and Akçalı, B. Y. (2016). The effect of innovation on financial performance of some information and technology companies in Turkey. Ekoist: Journal of Econometrics and Statistics, 24, 82-93.

Tays1, K. (2020). Determination of factors affecting active profitability by panel data analysis method. Journal of Orijinal Studies, 1(1), 15-30.

Temelli, F. ve Şahin, D. (2019). Yükselen piyasa ekonomilerinde finansal gelişme, ekonomik büyüme ve teknolojik gelişmenin çevresel kalite üzerine etkisinin analizi. Karabük Üniversitesi Sosyal Bilimler Enstitüsü Dergisi, 9(2), 577-593.

Uluyol, O. ve Türk, V. E. (2013). Finansal Rasyoların Firma Değerine Etkisi: Borsa İstanbul (BİST)'da Bir Uygulama. Afyon Kocatepe Üniversitesi İ̈BF Dergisi, 15(2), 365-384.

Uygurtürk, H. ve Korkmaz, T. (2012). Finansal performansın TOPSIS çok kriterli karar verme yöntemi ile belirlenmesi: ana metal sanayi işletmeleri üzerine bir uygulama. Eskişehir Osmangazi Üniversitesi IIIBF Dergisi, 7(2), 95-115.

Vurur, N. S. and İlarslan, K. (2016). Analysis of the relationship between R\&D expenditure and profitability: A sample application from BIST. Journal of Multidisciplinary Developments, 1(1), 103-112.

Yerdelen Tatoğlu, F. (2013). Panel Veri Ekonometrisi. İstanbul: Beta Yayınları.

Yıldırım, H. ve Sakarya, Ş. (2018). Firmaların Ar-Ge harcamalarının aktif ve özsermaye kârlılığına etkisi: BİST teknoloji sektöründe bir uygulama. Işsletme Bilimi Dergisi, 6(3), 39-60.

Zahra, S. A. and Das, S. R. (1993). Innovation strategy and financial performance in manufacturing companies: an empirical study. Production and Operations Management, 2(1), 15-37.

Zhu, Z. and Huang, F. (2012). The effect of R\&D investment on firms' financial performance: evidence from the Chinese listed IT firms. Modern Economy, 3(1),9 15-919. 


\section{Extended Abstract}

\section{Introduction}

Recently, the increase in the number of enterprises in many sectors highlights the phenomenon of sustainability. Businesses that want to generate more revenue and gain customers from their competitors have to differentiate by highlighting innovation in their products or services and turn it into a business philosophy. Shumpeter (1934) states that innovation manifests itself in five different ways in businesses. Types of innovation accordingly are to introduce a new product, obtaining the raw materials of the products from different sources, differentiation in production technique, operating in new markets and market differentiation.

It can be stated that the performance of enterprises that adopt innovation will be better against their competitors. Damanpour (1991), Khan et al. (1998), Cho and Pucik (2005), Orfila-Sintes and Mattsson (2009), Pioneer et al. (2015) and Şişmanoğlu and Akçalı (2016) are among the studies in the literature on how innovation improves business performance. In this study, it was aimed to investigate the effect of innovation on financial performance. In this context, data for a total of 20 periods, including a quarter in 2016-2020, of companies located in the manufacturing sector and operating in the automotive sector in Borsa Istanbul, were included in the analysis and the impact of innovation on financial performance was examined.

\section{Method}

Data containing the change of variable values according to time units is defined as a time series; data collected from different units at a certain point in time refers to horizontal cross-section data. Depending on the purpose of the study, some studies (Akgün and Akgün, 2016; Vurur and Ilarslan, 2016) consider only the time dimension, while some studies (Lantz and Sahut, 2005; Pabuccu and Imamoğlu, 2017) consider different units for a single period. Series created by combining horizontal cross-section observations of units for a certain period are called panel data sets (Yerdelen Tatoğlu, 2013: 2). Panel data sets, which include both time and horizontal cross-section observations, facilitate the analysis of complex models and provide better determination of unobserved effects (Akça, 2018). Thus, stronger estimates of econometric data can be realized.

In Panel data analysis, there are various models that differ according to the characteristics of units and/or time. Estimates are made using the Pooled Least Squares (POLS) method in classic models where the fixed and slope parameters do not change according to units and time. But in the case of different units, the coefficients contained in the classic model for different periods of time can take different values. In this case, the model becomes difficult to predict. For this reason, different models are usually used when performing panel data analyses according to the characteristics of error terms and the fact that the coefficients can vary (Pazarlioglu and Kiren Gurler, 2007: 37). In cases where the classical model is not suitable, the corresponding models are called "fixed-effect models" or "randomeffect models" according to the assumptions of unit and/or time effects. If Unit effects that cannot be observed in the research model are treated as a random variable, such as an error term, these models constitute a model of random effects, but if these unit effects are considered a constant parameter, these models constitute a model of fixed effects. (Yerdelen Tatoğlu, 2013: 79).

Zhu and Huang (2012), Apergis and Sorros (2014), Kocamış and Güngör (2014), hazelnut and January (2016), Doğan and Yıldız (2016), Yıldırım and Sakarya (2017), Özer et al. (2019), Taysi (2020) and Sevim (2021) used the values of active profitability ratio (ROA) and equity profitability ratio (ROE) as indicators of financial performance of an enterprise in their studies. Also, Zhu and Huang (2012), Apergis and Sorros (2014), Dagli and Ergün (2017), Demir and Güleç (2018), Özer et al. (2019), Güzen and Başar (2019) were considered the R \& D expense. The aim of this study is to investigate the impact of innovation on financial performance in businesses operating in the automotive manufacturing sector. For this purpose, data for 9 enterprises reporting R \& D expenditures in the annual reports were obtained 
from the annual and financial reports on the Public Disclosure Platform (KAP) website. In addition, a total of 20 periods of 2016Q1-2020Q4 were examined within the scope of the analysis.

\section{Findings}

For two different models created according to ROA and ROE dependent variables, it was investigated whether there were unit and / or time effects and it was decided that there were unit and / or time effects for both models. Hausman test was applied to decide whether these effects are constant or random. As a result of the Hausman test, it was decided that the random effects model was appropriate for Model I, for which the ROA variable is the dependent variable, while Model II, which was created based on the ROE indicator, was determined to be suitable for the fixed effects model. Fixed variance, autocorrelation and inter-unit non-correlation features of the estimation of model parameters were also examined and it was observed that the assumptions for research models were not met. In this case, test statistics that consider the assumption violations are used to estimate the model parameters.

\section{Conclusion, Discussion and Recommendations}

It has been observed that there is a significant and positive relationship between R\&D and ROA and ROE for both models created to determine the effect of R\&D investments on the financial performance of enterprises. In other words, the R\&D investments made show that the companies increase their return on assets and return on equity. The results of this study; Han et al. (1998), OrfilaSintes and Mattsson (2009), Apergis and Sorgis (2014), Öncü et al. (2015), Doğan and Y1ldız (2016), Dağlı and Ergün (2017), Gürkan and Gürkan (2017) and Yıldırım and Sakarya (2017) has been. It can be assumed that it contributes to the literature since the data used in the study are created from up-todate data and the analysis is performed on the automotive sector, which is a very open sector to innovation. In later studies, different results will be obtained by including businesses in different sectors to the analysis and increasing the number of variables to be included in the analysis. 